\title{
Chronic Cold Stress Reduces the Spontaneous Activity of Ventral Tegmental Dopamine Neurons
}

\author{
Holly Moore, Ph.D., Heather J. Rose*, M.S., and Anthony A. Grace, Ph.D.
}

The dopamine (DA) neurons in the ventral tegmental area and medial substantia nigra $(V T A / m S N)$ projecting to the limbic forebrain and prefrontal cortex have long been postulated to play a major role in cognitive and behavioral effects of stress. In this study, the effects of a chronic stressor (prolonged exposure to cold) on the spontaneous activity of DA neurons in the VTA/mSN were examined. Extracellular single-unit recordings of DA neurons were performed in rats following a 17-day continuous exposure to a cold $\left(4^{\circ} \mathrm{C}\right)$ environment. Compared to controls, coldexposed rats displayed $64 \%$ fewer spontaneously active DA neurons. The average spike activity (average firing rate, average spikes fired in bursts) of the DA cells that remained active in the cold-exposed rats did not differ significantly from controls. However, a significantly larger proportion of those cells showed excessive burst activity, compared to the DA cell population in controls. These results show that chronic stress can lead to the cessation of spontaneous activity in a subpopulation of VTA/mSN DA cells. These changes may indicate that unlike acute stress, which can potently activate the mesolimbic/mesocortical DA systems, chronic stress leads to an adaptive reduction in the number of active DA cells, perhaps altering the response of these systems to subsequent stressors.

[Neuropsychopharmacology 24:410-419, 2001]

(C) 2001 American College of Neuropsychopharmacology.

Published by Elsevier Science Inc.
KEY WORDS: Ventral tegmental area; Nucleus accumbens; Prefrontal cortex; Dopamine neurons; Stress; Dopamine release

Stress-induced changes in forebrain dopamine (DA) transmission have been implicated in the symptomatology of a number of psychiatric disorders including schizophrenia (Grace 1991; Seeman et al. 1976), major

From the Departments of Neuroscience (HM, HJR, AAG) and Psychiatry (AAG), University of Pittsburgh, Pittsburgh, PA.

Address correspondence to: Holly Moore, Ph.D., Department of Neuroscience, 446 Crawford Hall, University of Pittsburgh, Pittsburgh, PA 15260. Tel: (412) 624-4609; Fax: (412) 624-9198.

Received February 24, 2000; revised July 26, 2000; accepted August 2, 2000.

${ }^{*}$ Current Address: Department of Neurobiology and Behavior, University of California, Irvine, Irvine, CA 92697 depression (Anisman and Zacharko 1990; Willner 1995), and behavioral disorders related to drug abuse (Quick et al. 1986). The mesoaccumbens and mesocortical DA systems, comprised of cells in the ventral tegmental area (VTA) and medial substantia nigra pars compacta (mSN) projecting to the medial prefrontal cortex (mPFC) or nucleus accumbens (NAc; Fallon and Loughlin 1995), have been shown to be sensitive to a number of stressors (Horger and Roth 1996). For example, multiple studies have shown that rodents exposed acutely to a stressor such as tail shock, foot shock or restraint exhibit marked increases in extracellular DA levels in the mPFC and moderate increases in the NAc and/or striatum (Abercrombie et al. 1989; Roth et al. 1988; Thierry et al. 1976; for review, see Finlay and Zigmond 1997). Moreover, whereas mild stressors fail to increase DA levels in the NAc and dorsal striatum, they can evoke significant increases in prefrontal cortical DA 
levels (Abercrombie et al. 1989). Similar results have been shown with respect to measures of the DA metabolite DOPAC in the frontal cortex and NAc (Herman et al. 1982; cf. Horger and Roth 1996; Tissari et al. 1979). Thus, it appears that the DA projections from the VTA and substantia nigra are systematically activated during acute stress, with the sensitivity to stress being highest in the mesocortical DA system.

Although the changes in mesoaccumbens and mesocortical DA transmission following acute exposure to a stressor have been well characterized, less is known about the response of these systems to chronic stress or exposure to highly traumatic conditions. However, there is evidence that DA release in the NAc and PFC may show some adaptation to the stressor after repeated (Cabib and Puglisi-Allegra 1996; Imperato et al. 1992, 1993) or chronic (Gresch et al. 1994; Mizoguchi et al. 2000) exposure. Finlay et al. (1995) have shown that following chronic exposure to inescapable cold, considered a chronic stressor, extracellular DA levels in the NAc and PFC are unchanged or slightly lower than in controls (Gresch et al. 1994). Moreover, examined across studies, DA efflux evoked by a novel stressor appears to be similar in cold-stressed and control rats (Finlay et al. 1995; Gresch et al. 1994). Thus, it appears that in contrast to their responses to acute stress, the mesocortical and mesolimbic DA systems may show adaptation in response to chronic stress (see also Ortiz et al. 1996). The DAergic response contrasts with the sensitization of the sympathetic innervation to the adrenals and heightened response of the NE-containing neurons of the locus coeruleus in cold-stressed rats (Finlay et al. 1995; Fluharty et al. 1985; Gresch et al. 1994; Jedema et al. 1999, 2001; Mana and Grace 1997). This potentially distinct response of midbrain DA neurons to chronic stress may be relevant to the anhedonia and psychomotor slowing associated with post-traumatic stress disorder (Yehuda and Antelman 1993) and some forms of major depression (Willner 1995) and anxiety (Craig et al. 1995), given that these illnesses are induced or exacerbated by prolonged or severe stress (Brown 1993; Craig et al. 1995; Yehuda and Antelman 1993). The effects of chronic stress on the mesolimbic DA system may also be relevant to stress-induced exacerbation or relapse of psychoses (Zubin and Spring 1977; O'Conner 1991).

Whereas numerous studies have provided information regarding the effects of chronic or repeated stress on DA use or release in terminal regions, no data are available relating the effects of chronic stress to the electrophysiological activity of DA neurons. Therefore, the aim of the present study was to assess the effect of chronic cold exposure on the spike activity of DA neurons in the VTA/mSN. Accordingly, in control and cold-stressed rats, the number of spontaneously active DA cells and their average activity were determined with a systematic sampling of the VTA/mSN. In addition, the level of burst firing was measured, given that burst firing in DA cells has been shown to release significantly more DA per spike than when the cell is firing single spikes (i.e., independent, randomly spaced spikes) at an equivalent rate (Gonon 1988). Thus, the firing patterns, as well as overall activity of the population of DA cells, were considered to be significant indicators of the response of the mesolimbic/mesocortical DA systems to stress. These effects are discussed within the context of the effects of chronic stress on other catecholaminergic systems.

\section{METHODS}

\section{Subjects}

Male Sprague-Dawley rats weighing 150-175 g were obtained from Hilltop Laboratories (Scottdale, PA) and double-housed in wire mesh cages. The room was maintained at $22^{\circ} \mathrm{C}$ on a $12: 12 \mathrm{hr}$ light:dark schedule. Purina Rat Chow and water were available ad libitum. Animal care was carried out in accordance with guidelines set by the USPHS Publication Guide for the Care and Use of Laboratory Animals and all procedures were approved by the Institutional Animal Care and Use Committee of the University of Pittsburgh.

\section{Cold Stress}

Upon reaching a body weight of 200-225 g, rats were randomly assigned to a cold-stress or control group. The cold-stress subjects were partially shaved, such that the hair posterior to the forelimbs was shortened to approximately $1 / 8$ of an inch. This procedure has been shown previously to increase the effect of the cold exposure on sympathetic input to the adrenal glands, but does not disrupt adaptive (i.e., thermoregulatory) behaviors such as nesting and feeding (Van Zoeren and Stricker 1977). The effects of clipping on core body temperature have been shown to be minimal in rats during acute exposure to cold; moreover, physiological differences in shaved and unshaved animals housed in the cold environment do not appear until at least one week of cold exposure (Fluharty et al. 1985). Thus, partial shaving was used because of its effectiveness in increasing the effect of the cold on catecholamine systems and its minimal direct effects on body temperature and adaptive thermoregulatory behaviors. Partially shaved animals were housed in a $4^{\circ} \mathrm{C}$ room on a 12:12 hr light:dark schedule. Purina Rat Chow and water were available ad libitum. The subjects remained in the cold environment for 17 to 20 days and were then removed 18 to $20 \mathrm{hr}$ prior to experimentation, at which time they were returned to a $22^{\circ} \mathrm{C}$ 
room where they continued to be housed singly. Symptoms of physical distress, including redness on the ears or tail, red-colored lacrimation, rhinorea, or disruptions in eating behavior or weight gain resulted in removal of the subject from the experiment. To monitor the effects of prolonged cold exposure, spontaneous behaviors and body temperature were recorded during cold exposure and after re-exposure to the warm environment in a parallel experiment.

Control subjects were housed singly for 17 to 20 days at $22^{\circ} \mathrm{C}$ on a $12: 12 \mathrm{hr}$ light:dark schedule. Water was available ad libitum, but food was slightly restricted (approximately 3-4 g of Purina Rat Chow per day) to control for the slight decrease in the rate of weight gain of the subjects in the $4^{\circ} \mathrm{C}$ room. Rats in both groups were handled daily to decrease the acute stress of presurgical handling and injection of anesthetic (Ottenweller 2000).

\section{Electrophysiological Recordings}

The subjects (265-340 g) were anesthetized with chloral hydrate $(400 \mathrm{mg} / \mathrm{kg}$, i.p.) and placed in the stereotaxic apparatus. Body temperature was determined in a subset of rats at 15-20 min following injection of chloral hydrate, prior to surgery. Once the rats were stably anesthetized, the skull and dura overlying the VTA/ $\mathrm{mSN}$ were removed. Animals remained anesthetized for the remainder of the experiment. Depth of anesthesia was monitored by testing the foot withdrawal reflex, with additional anesthetic ( $4 \%$ chloral hydrate in saline) administered as needed. Body temperature was monitored by a rectal probe (Digital Thermometer, VWR Scientific Inc., Chicago, IL); core body temperature of $37 \pm 0.5^{\circ} \mathrm{C}$ was maintained by a thermostatically controlled heating pad (Fintronics VL-20F, Orange, CT).

Single unit extracellular recordings were used to measure the firing rate and firing pattern of DA cells in the VTA/mSN. Electrodes were pulled from $2.0 \mathrm{~mm}$ o.d. Omegadot glass tubing using a Narishige Vertical Electrode Puller and the tip was broken back to approximately $1 \mu \mathrm{m}$ under microscopic control. The electrode was then filled with $2 \mathrm{M} \mathrm{NaCl}$ saturated with $2 \%$ Pontamine Sky Blue; electrode impedance was 8-12 MO$\mathrm{hms}$. Signals were amplified by a preamplifier/window discriminator (Fintronics, Inc., Orange, CT) connected to a high-impedance head stage amplifier with window discriminator and were monitored by a Tektronics 7613 Storage Oscilloscope and Grass AM-8 audio monitor. Data were continuously digitalized by a Neurocorder DR-890 A/D converter (Cygnus Technologies, Delaware Water Gap, PA) and stored both on VHS videotapes and on a hard drive using a data acquisition board (Microstar Labs, Bellevue, WA) interfaced with a Microsoft
Windows-based Pentium PC. Analysis was performed with custom-designed software (Neuroscope $\odot$ ). Action potentials were isolated using a time and amplitude window discriminator integral to the preamplifier.

In each subject, the number and average activity of spontaneously active neurons in the VTA/mSN was sampled by systematically recording from 6 tracks within this region. The method of sampling multiple tracks is a well-accepted method for estimating population activity of the midbrain DA neurons (c.f. Grace et al. 1997; Moore et al. 1998). Thus, the electrode was lowered from the surface of the brain (coordinates $3.2 \mathrm{~mm}$ anterior to lambda and $1.1 \mathrm{~mm}$ lateral to midline) by a Kopf model 640 hydraulic micropositioner to a depth of $6 \mathrm{~mm}$. Action potentials from DA cells isolated by the electrode in the vertical tract between 6 and $9 \mathrm{~mm}$ from the brain surface were recorded. DA neurons within the track were identified by previously established criteria including an irregular or burst-firing pattern and a long duration biphasic action potential with a prominent negative phase (Grace and Bunney 1983). Following the sampling of a track, the electrode was then retracted and moved $200 \mu \mathrm{m}$ along the mediolateral or anteroposterior axis to a new location; a total of 6 tracks were recorded by this method.

Following the recording session the location of the electrode tip was marked by the iontophoretic ejection of Pontamine Sky Blue dye by passing $-28 \mu \mathrm{A}$ constant current through the electrode for $30 \mathrm{~min}$. Animals were then further anesthetized with chloral hydrate and perfused with saline followed by $10 \%$ formalin. Placement of dye deposit from the electrode was confirmed in Nissl-stained sections.

\section{Data Collection and Analysis}

The following measures of basal activity were determined: (1) the number of spontaneously active cells (average number of cells per electrode track), (2) the firing rate (average number of spikes/second per cell), and (3) the percentage of spikes fired within bursts per cell. A DA cell burst was defined by the criteria of Grace and Bunney (1984), with the beginning of a burst being defined as the occurrence of two spikes with an interspike interval of $\leqslant 80 \mathrm{~ms}$, and the termination of the burst defined by the occurrence of two spikes with an interspike interval of $\geqslant 160 \mathrm{~ms}$. The effect of chronic stress on the number of spontaneously active DA cells per track, baseline firing rate, and the percentage of spikes fired in bursts was evaluated using independent $t$-tests. In addition, a difference in the proportion of the spontaneously active DA cell population that fired more than $50 \%$ of their spikes within bursts was determined using a Chi Square test. 


\section{RESULTS}

\section{Effects of Prolonged Exposure to Cold on Body Temperature and Spontaneous Behavior}

Observations during this study indicated that rats housed in the cold showed signs of having performed normal food hoarding and "nesting" with the extra food pellets. The body temperature of rats housed in the cold for 9 days, at which time adrenal TH activity is significantly affected (Fluharty et al. 1985), was similar to non-stressed rats (rectal temperature in non-stressed rats, $37.43 \pm 0.06^{\circ} \mathrm{C}$; cold-exposed, $37.55 \pm 0.18^{\circ} \mathrm{C}\left[\mathrm{t}_{14}=\right.$ $0.68, p>.5])$. These responses indicate that during prolonged exposure to cold, rats are able to maintain thermal homeostasis. After removal from the cold, these rats displayed normal nesting behaviors. Moreover, grooming and burrowing in response to light handling appeared normal, or slightly more prolonged, in cold-exposed rats that had been removed from the cold for 18-20 hr. These observations are consistent with previous reports that the shaving procedure and coldexposure does not result in a gross disruption of spontaneous behavior (e.g., Van Zoeren and Stricker 1977).

To observe a possible difference in the effects of chloral hydrate on thermoregulation in cold-stressed and control rats, core body temperature and respiration rate were recorded following injection of chloral hydrate in a subset of rats. In both control $(n=3)$ and coldstressed $(n=3)$ rats, as the chloral hydrate took effect, respiration rate first increased then began to decrease, whereas body temperature began to drop at the point that respiration stabilized (this occurred at about 15-20 min post-injection). At this point, cold-stressed rats did not differ from controls with regard to respiration (controls: $71.5 \pm 38 \mathrm{~Hz}$, cold-stressed: $69 \pm 17 \mathrm{~Hz}$ ) or body temperature (controls: $37.1 \pm 0.36^{\circ} \mathrm{C}$, cold-stressed: $37.2 \pm$ $0.42{ }^{\circ} \mathrm{C}$ ). During recording, there were no observable differences between the heating pad settings required to maintain the body temperature of control vs. coldstressed rats.

\section{Location of Recording Sites}

Data were analyzed only from rats in which the histological analysis revealed that the recording sites lay within the VTA or the substantia nigra medial to the medial lemniscus. Recording tracks terminated approximately $1.2 \mathrm{~mm}$ from midline in the DAergic cell body region lying just medial to substantia nigra pars compacta and ventromedial to the medial lemniscus.

\section{Cells per Track, Firing Rate, and Percentage of Spikes Fired in Bursts}

In cold-stressed rats that had been removed from the cold for 18-20 hr, there were significantly fewer sponta- neously active DA cells observed in 6 recording tracks in the VTA/mSN, with cold-exposed rats showing $64 \%$ fewer DA neurons than controls, as revealed by an independent $t$-test $\left(\mathrm{t}_{22}=3.3, p<.01\right.$, Figure 1A). Control animals had $1.01 \pm 0.13$ (mean \pm SEM) cells per track $(n=$ 10) whereas cold-stress animals exhibited $0.37 \pm 0.13$ cells per track $(n=14)$. The firing rate and the average percentage of spikes fired in bursts of the active DA cells were not significantly different in stressed versus control animals (Figure 1B, 1C). Control and coldstressed animals had average firing rates of $3.69 \pm 0.46$ $\mathrm{Hz}$ and $3.31 \pm 0.49 \mathrm{~Hz}$, respectively $\left(\mathrm{t}_{17}=-0.56, p>\right.$ $.05)$. Control and cold-stressed animals showed an average of $24.2 \pm 5.8$ and $32.4 \pm 8.8 \%$ spikes in bursts, respectively $\left(\mathrm{t}_{17}=-1.49, p=-.16\right)$. However, the distribution of bursting across VTA/mSN DA cells was different in control versus cold-treated rats, with the cold-treated rats showing a subpopulation of neurons that exhibited markedly higher levels of burst firing (Figure 2). In control animals, only a minority (14\% [8/ 57]) of spontaneously active VTA/mSN DA neurons fired $>50 \%$ of their spikes in bursts. In cold-stressed rats, a significantly greater proportion $[25 \%(6 / 24)]$ of neurons of the VTA/mSN DA neurons displayed this high rate of bursting $\left(\chi^{2}=4.8 ; p=.03\right)$.

\section{DISCUSSION}

The present study is the first to examine the effect of a chronic stressor (cold stress) on the electrophysiological activity of mesolimbic or mesocortical DA neurons. Following chronic cold exposure, a subpopulation of DA neurons in the VTA/mSNc ceased to spontaneously fire action potentials, while the population that remained active showed altered firing patterns compared to control neurons. These results indicate that chronic inescapable stress may impose long-lasting changes in the regulation of neuronal activity of mesolimbic and/ or mesocortical DA neurons. The results have relevance for the role of mesolimbic and mesocortical DA systems in both adaptive and pathological behavioral responses to environmental stressors.

\section{Influence of Anesthesia}

One potential concern in interpreting the decrease in DA cell spontaneous activity found in the chronically stressed rats is a possible interaction with the effects of anesthesia on DA cell activity and thermoregulation. However, in the present study, changes in body temperature appeared to be similar in cold-stressed and control rats following administration of the anesthetic. Furthermore, studies have shown that chloral hydrate anesthesia exerts minimal effects on both DA cell activity (a slight increase in activity and blunted response to 


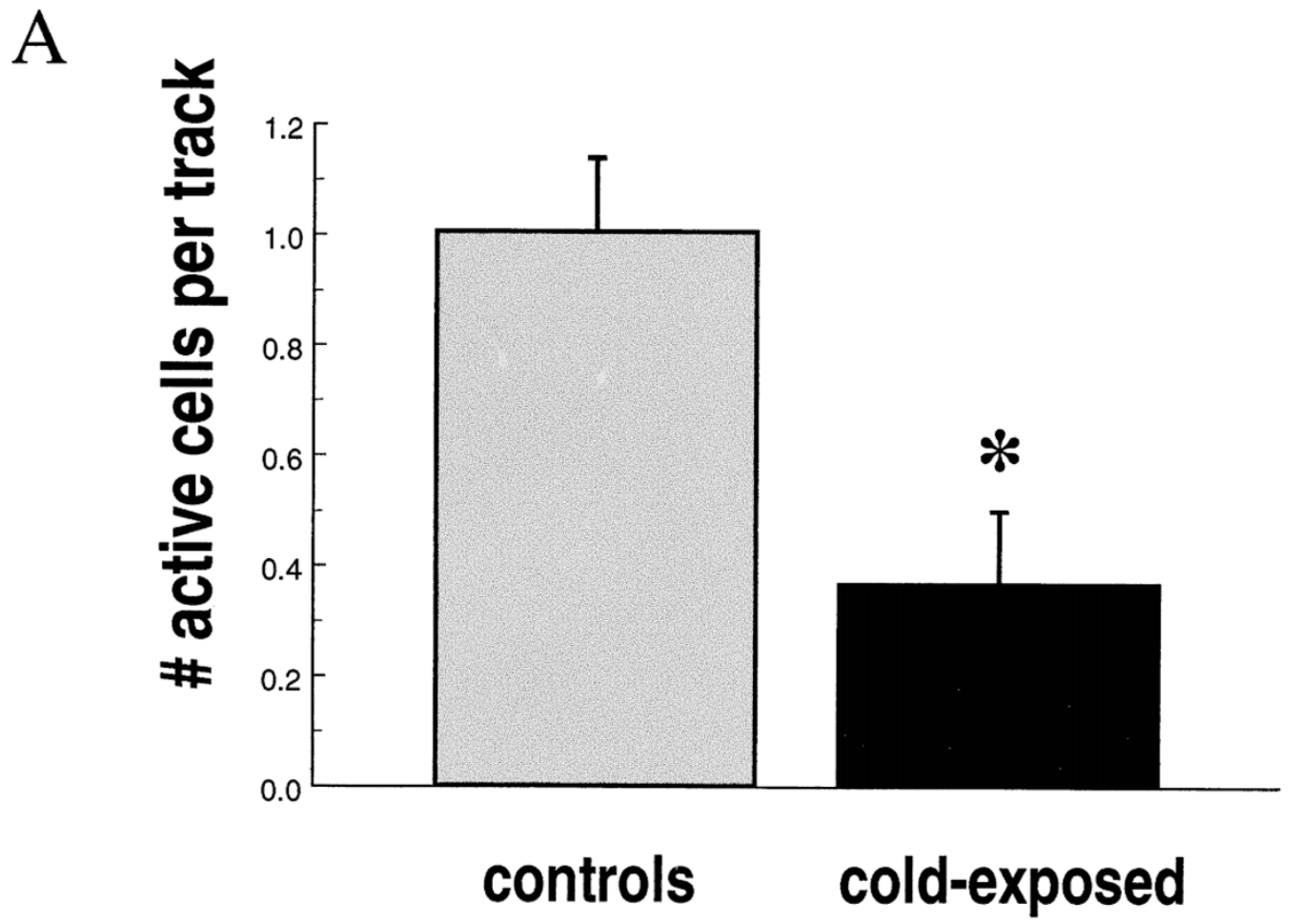

B
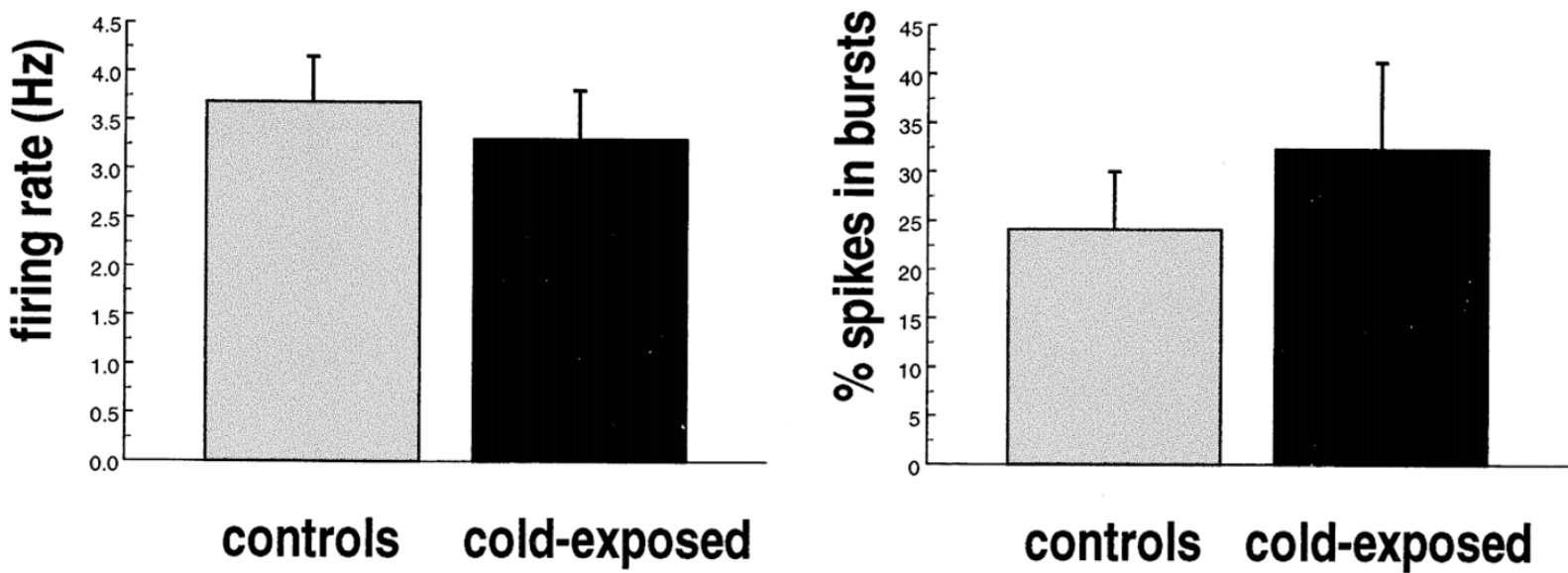

controls cold-exposed

Figure 1. Activity states of DA neurons in control rats compared to those in rats exposed to chronic cold stress. (A) The average number of spontaneously active DA neurons recorded per electrode track was significantly lower $\left({ }^{*} p<.001\right)$ in rats exposed to 17 days of cold when compared to controls. (B) The average firing rate (left) and the average percentage of spikes fired in bursts (right) in the spontaneously active neurons recorded in cold-exposed rats were not significantly different than those recorded in control rats.

DA receptor antagonists; Bunney et al. 1973) and DA efflux in the striatum (Chen and Kandasamy 1996). Thus, given that the complex stressor used in this experiment (i.e., exposure to cold and return to room temperature) appeared to have little effect on body temperature and thermoregulatory behaviors near the time of testing, and given the known minimal effects of chloral hydrate on DA cell activity, it is unlikely that the effect observed in the cold-stressed rats was confounded by an anesthesia-induced depression of DA cell activity. On the other hand, anesthesia necessarily depresses the cortical and other forebrain inputs to the VTA neurons. Given that 


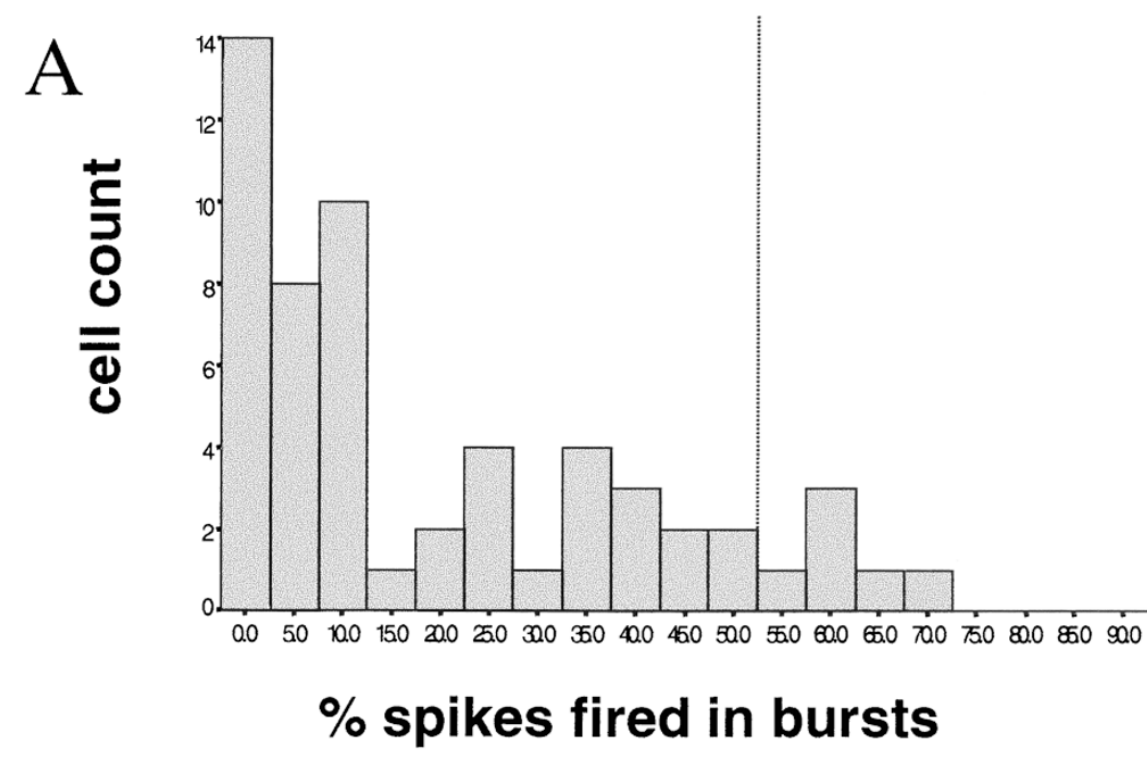

B

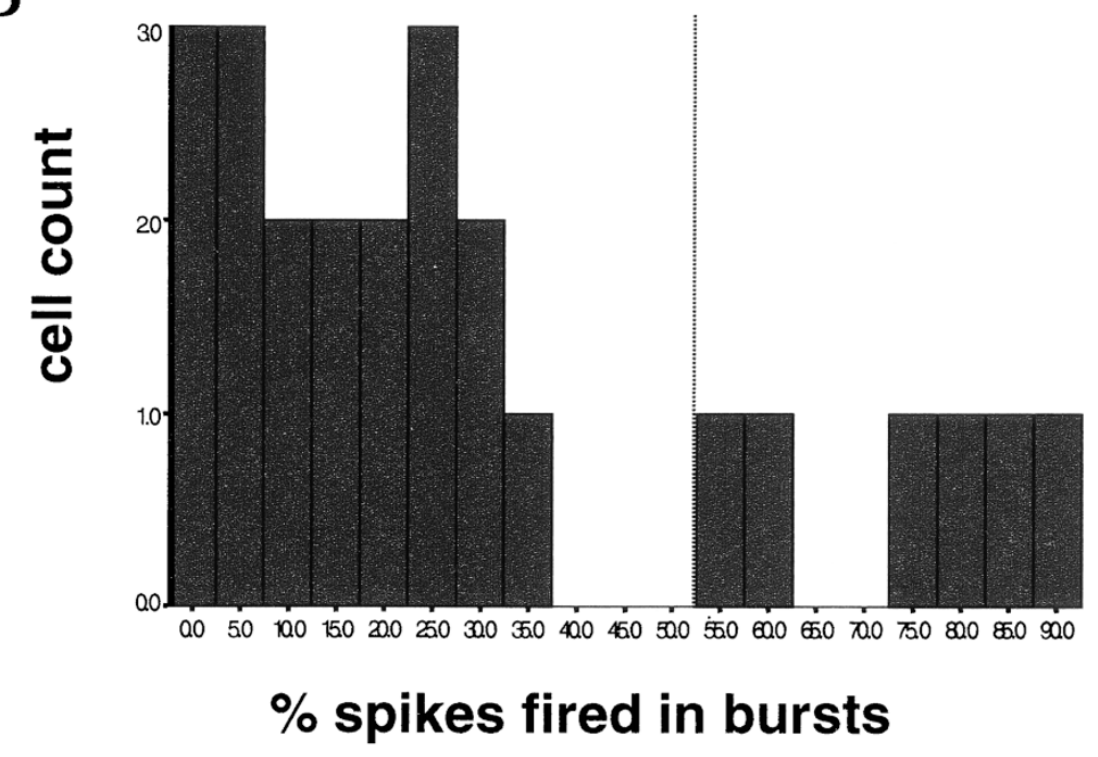

Figure 2. Distribution of DA neurons from control (A) and coldstressed (B) rats with respect to the proportion of spikes of fired in bursts. In the cold-stressed rats, a significantly higher number of DA neurons were classified as rapidly bursting neurons, in that they displayed more than $50 \%$ of their spikes in bursts $\left(\chi^{2}=4.8 ; p=.03\right)$. Neurons depicted to the right of the vertical lines were considered to be rapidly bursting cells. Note that the ranges of the ordinates differ in order to display proportion of rapidly bursting cells. these inputs are likely to regulate the firing of VTA DA neurons during the expression of goal-directed behavior (c.f., Moore et al. 1999), an examination of the effects of chronic stress on the forebrain inputs to VTA DA neurons will be critical in interpreting the effects of stress on limbic-related DA systems in the behaving animal.

\section{Prolonged Exposure to Cold as a Stressor}

The stressor used in this study is complex, consisting of a partial shaving procedure, prolonged exposure to cold, and removal from cold and reintroduction to room temperature. Consistent with a previous study
(Van Zoeren and Stricker 1977), we observed no qualitative changes in the rats' thermoregulatory behavior during cold exposure or grooming following removal from cold. Moreover, at least two studies have indicated that the shaving procedure has no significant effect on the animal during the first week of cold exposure, indicating that the effects of shaving per se do not cause immediate distress to the animal. However, the severity of the cold is enhanced in shaved rats following 1 week of cold-exposure, thus the reduction in fur contributes significantly to the severity of the chronic stressor (Fluharty et al. 1985). It is also not unlikely that re-adaptation to room temperature environment also comprises a significant component of the stressor. 
However, as noted, at $18-24 \mathrm{hr}$ following removal from the cold, spontaneous behaviors and core body temperature were not different in cold-exposed rats when compared with controls.

Previous work has shown that initial responses to cold-restraint include elevation of plasma corticosterone (e.g., Dallman et al. 2000) increases in tyrosine hydroxylase mRNA and activity in the adrenal glands and locus coeruleus (Fluharty et al. 1985; Richard et al. 1988) and increases in release or turnover of cortical norepinephrine and dopamine (Dallman et al. 2000; Dunn and File 1983; c.f., Stanford 1993). These and other effects such as increased vulnerability to gastric ulcers have led to the conclusion that this procedure represents a relatively severe stressor that affects not only the exquisitely sensitive mesocortical dopamine system but also mesolimbic and nigrostriatal DA systems (Dunn and File 1983). Several studies have also looked at changes in the HPA axis and forebrain norepinephrine and dopamine systems that persist following removal of the stressor. For example, exposure to cold has been shown to sensitize ACTH release induced by a novel stressor (restraint; Dallman et al. 2000). Similarly, hippocampal and prefrontal cortical norepinephrine efflux has been shown to be significantly more responsive to a novel stressor (footshock) in previously cold-stressed rats (Finlay et al. 1995; Gresch et al. 1994; Jedema et al. 1999). This sensitization of stress-induced NE release is likely to be mediated at least in part by the increased responsivity of LC neurons to multiple excitatory inputs in animals recovered from cold exposure (Jedema et al. 2001; Mana and Grace 1997; Simson and Weiss 1988). These effects of cold stress are similar to those produced by swim stress (e.g., Curtis et al. 1999) and repeated immobilization stress manipulations that also produce a number of behavioral and pharmacological effects considered to model some forms of depression (Porsolt et al. 1977). Other stressors, such as exposure to intermittent unpredictable footshock, have been shown not to be sufficient to produce the sensitization of forebrain NE release. Thus, it would appear that the continual and unavoidable aspects of the cold stress contribute most to its effects on the nervous system. Whether all forms of inescapable stress produce similar changes in VTA DA cell activity remains to be determined. In addition, how long these changes persist beyond the cessation of the stressor will be an important determinant of the relevance of this paradigm to stress-related psychiatric illnesses (Yehuda and Antelman 1993).

\section{Stress-induced Changes within the Dopamine System}

Prior to the present study, no data were available on the effect of chronic or repeated stress on DA neuron activ- ity. The only previous experiments relevant to stress were those showing that a noxious stimulus applied to the tail or foot of an anesthetized rat induces a brief inhibition often followed by an increase in spike firing in midbrain DA cells (Gao et al. 1990; Grace et al. 1980; Mantz et al. 1989; Maeda and Mogenson 1982). On the other hand, the effects of a variety of stressors on extracellular DA levels in the PFC and NAc have been relatively well-characterized. These studies have shown that chronic or repeated exposure to a stressor results in no change or a slight decrease in basal extracellular DA in the PFC and/or NAc (Finlay et al. 1995; Gresch et al. 1994; Imperato et al. 1992, 1993; Mizoguchi et al. 2000). Consistent with this, while cold stress reliably induces an increase in NE neuron excitability in the LC (Jedema et al. 2001; Mana and Grace 1997), it produces a decrease in active DA neurons. These two effects may not be independent of each other, since increased burst-firing in LC neurons prolongs the inhibition of DA neurons following LC stimulation (Grenoff et al. 1993). This, as well as differential changes in TH activity and gene expression in the LC and midbrain (Ortiz et al. 1996; Richard et al. 1988; Zigmond et al. 1974) may contribute to the apparent persistence and sensitization of the activation of forebrain NE transmission versus the apparent adaptation of the mesolimbic/mesocortical DA systems. It is important to note, however, that changes in DA release cannot be easily predicted from changes in neuronal firing rate. For example, Gonon (1988) and Suaud-Chagny et al. (1992) showed that stimulated DA release is more dependent on burst firing than on average firing rate. In the present study, there was a significantly greater proportion of rapidly bursting DA neurons in the cold-stressed rats when compared to controls; thus, extracellular DA levels may not be expected to be decreased in proportion to the decrease in the number of active DA cells. Therefore, while it is clear that a stress-induced cessation in spike activity could limit DA efflux, extracellular levels of DA at the terminal would also depend on the parallel effects on limbic forebrain inputs to DA cell bodies and terminals (Grace 1991; Moore et al. 1999).

In the present study, although chronic cold exposure produced a significant decrease in the number of spontaneously active VTA DA cells, there remained a significant level of residual activity in a sub-population of cells. The mechanism underlying this apparently heterogeneous response within the limbic-related DA neuron population is not known. One possible mechanism is increased autoinhibition of cell activity by $\mathrm{D} 2$ receptor activation in the VTA/mSN by local release of DA (e.g., Piercey et al. 1990). Although this may occur through chronic stress-induced increases in TH activity in the VTA (Otiz et al. 1996), in preliminary follow-up experiments to this study, systemic administration of the DA D2 receptor antagonist haloperidol did not appear to 
disinhibit DA neurons in cold-exposed rats $(n=3)$. On the other hand, the lack of difference in the average spike activity (i.e., firing rate and percentage of spikes fired in bursts) in the spontaneously active VTA/mSN DA neurons in cold-exposed rats points to the possibility that the exposure to cold stress inactivated a subpopulation of DA neurons, leaving the other population relatively unaffected. One possibility is that the cessation of spontaneous firing in a subpopulation of DA neurons is related to the differential response of the mesocortical and mesolimbic DA neurons to stress. These neurons are intermingled in the area that was sampled in the present study (Fallon and Loughlin 1995). Testing this hypothesis would require antidromic activation to confirm the terminal regions of a spontaneously active DA cell. Since such stimulation would have likely also stimulated forebrain projections to the VTA/mSN, affecting the population activity of the DA neurons, it was not performed in the present study.

\section{Relevance to Psychiatric Disorders}

Taken together, the present results and neurochemical literature suggest that in the normal organism, the DA system compensates for the presence of a chronic or repeated stressor, possibly by inactivating a subpopulation of DA neurons. This response may occur simultaneous with an increase in the sensitivity of the ascending NE projections (see above). Given the roles of forebrain NE and DA in attentional processes and goal-directed movement, respectively, this would result in a state in which the organism has heightened detection of subsequent noxious stimuli, without an increase in the motoric responses to such stimuli. Within limits, these changes may allow the animal to respond adaptively to novel stressors, in that the sensitized forebrain NE and sympathoadrenal responses would allow earlier detection of such stressors. At the same time, through inactivation of a population of DA neurons, extracellular DA levels would be "capped" but still able to reach normal levels (see Finlay et al. 1995; Gresch et al. 1994). These changes to the DA system may permit a range of behavioral responses to the novel stressor, but limit the extent of possibly maladaptive (i.e., energyconsuming) motoric activation (West 1990).

In the case of exposure to especially severe or prolonged stressors, the DA system may become further down-regulated, resulting in deficits in goal-directed behaviors. This process may, in part, underlie deficits in escape behavior (i.e., "learned helplessness") exhibited in animals following exposure to inescapable stress (Maier and Seligman 1976; Porsolt et al. 1977). These decreases in escape (i.e., goal-directed) behavior would be expected to be accompanied by increases in activity in central NE and HPA axis activity (Anisman and Zacharko 1990; Curtis et al. 1999; Dallman et al. 2000).
Similarly, the down-regulation of midbrain DA neurons occurring along with the sensitization of forebrain $\mathrm{NE}$ and sympathetic systems may, in part, underlie the increased vigilance (especially with regard to novel or noxious stimuli) and decreased goal-directed behavior (e.g., psychomotor poverty, rumination) associated with PTSD (Yehuda and Antelman 1993), as well as some forms of major depression and generalized anxiety (Craig et al. 1995; Willner 1995). On the other hand, a pathological down-regulation of the forebrain DA systems, resulting from prior exposure to stress or a congenital or insult-induced pathology in limbic-related cortical regions (Grace 1991) might lead to an increased vulnerability to subsequent stress. Indeed, the lower baseline activity state could lead to post-synaptic changes that would allow DA cell firing to exert a greater effect, possibly resulting in hyperactivity in response to novel, non-noxious stimuli (e.g., Grace 1991; Stanford 1993). Such a mechanism may contribute to both to the manifestation of psychosis during severe depressive episodes and to stress-related relapse of psychosis in schizophrenia patients (O'Conner 1991; Zubin and Spring 1977). Finally, it is noted that central DAergic responses to stress have been shown to be highly dependent on the nature of the stressor (Stanford 1993). One hypothesis supported by the present results is that the effects of stress may be specific for a subset of DAergic neurons. Given the roles of mesolimbic and mesocortical DA systems in adaptive behavior, and the disruption of such behavior by chronic or severe stress in animal models and psychiatric disorders, it will be important to further characterize the effects of chronic stress on these systems.

\section{ACKNOWLEDGMENTS}

Research was supported by Howard Hughes Undergraduate Fellowship (HJR), a National Association for Research on Schizophrenia and Depression Young Investigator award (HM), an NIMH Individual NRSA (HM), and USPHS grants MH 45156, 29670 and 57440 (AAG). The authors thank Nicole MacMurdo for her technical assistance, Brain Lowry for development of Neuroscope $\odot$ physiological data analysis software, and Hank Jedema for his critical comments on an earlier version of this manuscript.

\section{REFERENCES}

Abercrombie ED, Keefe KA, DiFrischia DS, Zigmond, MJ (1989): Differential effect of stress on in vivo dopamine release in striatum, nucleus accumbens, and medial frontal cortex. J Neurochem 52:1655-1658

Anisman H, Zacharko RM (1990): Multiple neurochemical and behavioral consequences of stressors: Implications for depression. Pharm Theapeutics 46:119-136 
Brown GW (1993): The role of life events in the aetiology of depressive and anxiety disorders. In Stanford SC, Salmon P (eds), Stress: From Synapse to Syndrome. London, Academic Press, pp 24-52

Bunney BS, Walters JR, Roth RH, Aghajanian GK (1973): Dopaminergic neurons: Effect of antipsychotic drugs and amphetamine on single cell activity. J Pharmacol Exper Ther 49:560-571

Cabib S, Puglisi-Allegra S (1996): Different effects of repeated stressful experiences on mesocortical and mesolimbic dopamine metabolism. Neuroscience 73: 375-380

Chen HT, Kandasamy SB (1996): Effect of chloral hydrate on in vivo $\mathrm{KCl}$-induced striatal dopamine release in the rat. Neurochemical Res 21:695-700

Craig KJ, Brown KJ, Baum A (1995): Environmental factors in the etiology of anxiety. In Bloom FE, Kupfer DJ (eds), Psychopharmacology: The Fourth Generation of Progress. New York, Raven Press, pp 1325-1340

Curtis AL, Pavcovich LA, Valentino RJ (1999): Long-term regulation of locus ceruleus sensitivity to corticotropinreleasing factor by swim stress. J Pharmacol Exper Ther 289:1211-1219

Dallman MF, Bhatnagar S, Viau V (2000): Hypothalamopituitary-adrenal axis. In Fink $\mathrm{G}$ (ed), The Encyclopedia of Stress, vol 2, San Diego, Academic Press, pp 477-483

Dunn AJ, File SE (1983): Cold restraint alters dopamine metabolism in frontal cortex, nucleus accumbens and neostriatum. Physiol Behav 31:511-513

Fallon JH, Loughlin SE (1995): The subtantia nigra. In Paxinos G (ed), The Rat Nervous System. San Diego, Academic Press, pp. 215-238

Finlay JM, Zigmond, MJ (1997): The effects of stress on central dopaminergic neurons: possible clinical implications. Neurochemical Res 22:1387-1394

Finlay JM, Zigmond MJ, Abercrombie ED (1995): Increased dopamine and norepinephrine release in medial prefrontal cortex induced by acute and chronic stress: Effects of diazepam. Neuroscience 64:619-628

Fluharty SJ, Snyder GL, Zigmond M, Stricker EM (1985): Tyrosine hydroxylase activity and catecholamine biosynthesis in the adrenal medulla of rats during stress. J Pharmacol Exper Ther 233:32-38

Gao DM, Jeaugey L, Pollak P, Benabid AL (1990): Intensitydependent nociceptive responses from presumed dopaminergic neurons of the substantia nigra, pars compacta in the rat and their modification by lateral habenula inputs. Brain Res 529:315-319

Gonon FG (1988): Nonlinear relationship between impulse flow and dopamine release by rat midbrain dopaminergic neurons as studied by in vivo electrochemistry. Neuroscience 24:19-28

Grace AA (1991): Phasic versus tonic dopamine release and the modulation of dopamine system responsivity: A hypothesis for the etiology of schizophrenia. Neuroscience $41: 1-24$

Grace AA, Bunney BS (1983): Intracellular and extracellular electrophysiology of nigral dopaminergic neurons-1. Identification and characterization. Neuroscience 10: 301-315
Grace AA, Bunney BS (1984): The control of firing pattern in nigral dopamine neurons: burst firing. J Neuroscience 4:2877-2890

Grace AA, Bunney BS, Moore H, Todd CL (1997): Dopamine cell depolarization block as a model for the therapeutic actions of antipsychotic drugs. Trends Neuroscience 20:23-30

Grace AA, Hommer DW, Bunney BS (1980): Peripheral and striatal influences on nigral dopamine cells: Mediation by reticulata neurons. Brain Res Bull 5(Suppl 2):105-109

Grenoff J, Nisell M, Ferre S, Aston-Jones G, Svensson TH (1993): Noradrenergic modulation of midbrain dopamine cell firing elicited by stimulation of the locus coeruleus in the rat. J Neural Transm 93:11-25

Gresch PJ, Sved AF, Zigmond MJ, Finlay JM (1994): Stressinduced sensitization of dopamine and norepinephrine efflux in medial prefrontal cortex in the rat. J Neurochem 63:575-583

Herman JP, Guillonneau D, Dantzer R, Scatton B, Semerdjian-Rouquier L, LeMoal M (1982): Differential effects of inescapable footshock and of stimuli previously paired with inescapable footshock on dopamine turnover in cortical and limbic areas of the rat. Life Sci 30:2207-2214

Horger BA, Roth RH (1996): The role of mesoprefrontal dopamine neurons in stress. Critical Rev Neurobiol 10: 395-418

Imperato A, Angelucci L, Casolini P, Zocchi A, PuglisiAllegra S (1992): Repeated stressful experiences differently affect limbic dopamine release during and following stress. Brain Res 557:194-199

Imperato A, Cabib S, Puglisi-Allegra S (1993): Repeated stressful experiences differently affect the time dependent responses of the mesolimbic dopamine system to the stressor. Brain Res 601:333-336

Jedema HP, Finlay JM, Sved AF, Grace AA (2001): Chronic cold exposure potentiates $\mathrm{CRH}$-evoked increases in electrophysiological activity of locus coeruleus neurons. Biological Psychiatry, 49

Jedema HP, Sved AF, Zigmond MJ, Finlay JM (1999): Sensitization of norepinephrine release in medial prefrontal cortex: Effect of different chronic stress protocols. Brain Res 830:211-217

Maeda H, Mogenson GJ (1982): Effects of peripheral stimulation or the activity of neurons in the ventral tegmental area, substantia nigra and midbrain reticular formation of rats. Brain Res Bull 8:7-14

Maier SF, Seligman MEP (1976): Learned helplessness: Theory and evidence. J Exp Psychol (Gen) 1:3-46

Mana MJ, Grace AA (1997): Chronic cold stress alters the basal and evoked electrophysiological activity of rat locus coeruleus neurons. Neuroscience 8:1055-1064

Mantz J, Thierry AM, Glowinski J (1989): Effect of noxious tail pinch on the discharge rate of mesocortical and mesolimbic dopamine neurons: Selective activation of the mesocortical system. Brain Res 476:377-381

Mizoguchi K, Yuzurihara M, Ishige A, Sasaki H, Chue D, Tabira T (2000): Chronic stress induces impairment of spatial working memory because of prefrontal dopaminergic dysfunction. J Neuroscience 20:1568-1574

Moore H, Todd CL, Grace AA (1998): Extracellular dopa- 
mine in the striatum of rats with haloperidol-induced depolarization block in substantia nigra dopamine neurons. J Neuroscience 18:5068-5077

Moore H, West AR, Grace AA (1999): The regulation of forebrain dopamine transmission: relevance to the pathophysiology and psychopathology of schizophrenia. Biol Psychiatry 46:40-55

O'Conner FW (1991): Symptom monitoring for relapse prevention in schizophrenia. Arch Psychiatric Nursing 5:193-201

Ortiz J, Fitzgerald LW, Lane S, Terwilliger R, Nestler EJ (1996): Biochemical adaptations in the mesolimbic dopamine system in response to repeated stress. Neuropsychopharmacology 14:443-452

Ottenweller JE (2000): Animal models (nonprimate) for human stress. In Fink G (ed), Encyclopedia of Stress, vol 1, San Diego, Academic Press, pp 200-205

Quick JD, Horn RS, Quick JC (1986): Health consequences of stress. J Organiz Behav Manag 8:19-36

Piercey MF, Broderick PA, Hoffmann WE, Vogelsang GD (1990): U-66444B and U-68553B, potent autoreceptor agonists at dopaminergic cell bodies and terminals. J Pharmacol Exper Ther 254:369-374

Porsolt RD, Le Pinchon M, Jalfre M (1977): Depression: A new animal model sensitive to antidepressant treatments. Nature 266:730-732

Richard F, Faucon-Biguet N, Labatut R, Rollet D, Mallet J, Buda M (1988): Modulation of tyrosine hydroxylase gene expression in rat brain and adrenals by exposure to cold. J Neuroscience Res 20:32-37

Roth RH, Tam SY, Ida Y, Yang JX, Deutch AY (1988): Stress and the mesocorticolimbic dopamine systems. Ann N Y Acad Sci 537:138-147

Seeman P, Lee T, Chau-Wong M, Wong K (1976): Antipsychotic drug doses and neuroleptic/dopamine receptors. Nature 261:717-719

Simson PE, Weiss JM (1988): Altered activity of locus coeruleus in an animal model of depression. Neuropsychopharmacology 1:287-295
Stanford SC (1993): Monoamines in response and adaptation to stress. In Stanford SC, Salmon P (eds), Stress: From synapse to syndrome. London, Academic Press, pp 24-52

Suaud-Chagny MF, Chergui K, Chouvet G, Gonon F (1992): Relationship between dopamine release in the rat nucleus accumbens and the discharge activity of dopaminergic neurons during local in vivo application of amino acids in the ventral tegmental area. Neuroscience 49:63-72

Thierry AM, Tassin JP, Blanc G, Glowinski J (1976): Selective activation of mesocortical DA system by stress. Nature 263:242-244

Tissari AH, Argiolas A, Fadda F, Serra G, Gessa GL (1979): Foot-shock stress accelerates non-striatal dopamine synthesis without activating tyrosine hydroxylase. Arch Pharmacology 308:155-157

Van Zoeren JG, Stricker E (1977): Effects of preoptic, lateral hypothalamic, or dopamine-depleting lesions on behavioral thermoregulation in rats exposed to the cold. J Comp Physiol Psychol 91:989-999

West AP (1990): Neurobehavioral studies of forced swimming: The role of learning and memory in the forced swim test. Prog Neuropsychopharmacol Biol Psychiatry $14: 863-877$

Willner P (1995): Dopamine mechanisms in depression and mania. In Bloom FE, Kupfer DJ (eds), Psychopharmacology: The Fourth Generation of Progress. New York, Raven Press, pp 921-932

Yehuda R, Antelman SM (1993): Criteria for rationally evaluating animal models of posttraumatic stress disorder. Biol Psychiatry 33:479-486

Zigmond RE, Schon F, Iversen LL (1974): Increased tyrosine hydroxylase activity in the locus coeruleus of rat brainstem after reserpine treatment and cold stress. Brain Res 70:547-552

Zubin J, Spring B (1977): Vulnerability-a new view of schizophrenia. J Abnormal Psychol 86:103-126 